\title{
Laparoendoscopic Single-Site Hysterectomy: A Single Surgeon Experience in a Tertiary Hospital
}

\author{
Gokhan DEMIRAYAK ${ }^{1}$, Onur GURALP ${ }^{2}$, Mustafa YILDIZ ${ }^{3}$, Cihan COMBA ${ }^{1}$, Veli MIHMANLI ${ }^{3}$, Isa Aykut OZDEMIR ${ }^{1}$ \\ Istanbul, Turkey
}

\begin{abstract}
OBJECTIVE: To evaluate the clinical and surgical outcomes of the total hysterectomy cases performed with the laparoendoscopic single-site surgery.

STUDY DESIGN: A total of 24 women who underwent total hysterectomy by the laparoendoscopic single-site technique due to benign gynecological disorders were retrospectively evaluated. The duration of the operation, estimated blood loss, weight of the uterus, intra- and postoperative complications, preand postoperative day 1 hemoglobin and hematocrit levels, postoperative 6- and 24-hour visual analogue scale scores, duration of hospital stay, and postoperative complications were evaluated.
\end{abstract}

RESULTS: The mean total operation time was $112.1 \pm 24$ minutes. The average time between the umbilical incision and starting the hysterectomy was $10 \pm 2.1$ minutes. Estimated blood loss was $50 \pm 25 \mathrm{ml}$. The average duration of the hospital stay was $1.5 \pm 0.4$ days. The mean uterus weight was $135 \mathrm{~g}$. The mean difference between the pre- and postoperative hemoglobin values was $1.1 \mathrm{~g} / \mathrm{dl}$. The mean visual analogue scale scores were $4.1(0-7)$ and $1.9(0-4)$ in 6 - and 24 -hour postoperative periods. None of the women had an intraoperative complication. One patient $(4.2 \%)$ had a port site hernia 6 months after the operation.

CONCLUSION: The total hysterectomy with laparoendoscopic single-site technique is a reasonable method in selected patients with similar safety and feasibility, especially for women who prefer a single incision in umbilicus. The patient should be informed before the operation about potential complications such as a port-site hernia.

Keywords: Hernia, Hysterectomy, Laparoscopy, Laparoendoscopic single-site surgery, Minimally invasive surgery

Gynecol Obstet Reprod Med 2019;25(2):96-100

${ }^{1}$ Health Sciences University Bakırkoy Dr. Sadi Konuk Education and Research Hospital Department of Gynecologic Oncology, Istanbul

${ }^{2}$ Oldenburg University Department of Obstetrics and Gynecology Oldenburg, Germany

${ }^{3}$ Health Sciences University Okmeydani Education and Research Hospital Department of Obstetrics and Gynecology, Istanbul

Address of Correspondence: Onur Guralp

Rahel-Strauß Straße 10, 26133, Oldenburg, Germany Oldenburg University, Klinikum Oldenburg AöR, Obstetrics and Gynecology. dronur@hotmail.com

Submitted for Publication: $\quad 25.06 .2018$ Accepted for Publication: $\quad 12.10 .2018$

ORCID IDs of the authors:

G.D.: 0000-0002-5679-3199, O.G.: 0000-0002-3517-3046,

M.Y.: 0000-0002-8383-8874, C.C.. 0000-0002-3161-2689,

V.M.. 0000-0001-8701-8462, I.A.O.. 0000-0001-5457-3312

\begin{tabular}{|c|c|}
\hline \multirow{3}{*}{ 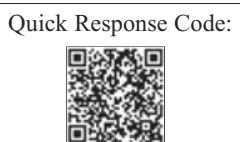 } & Access this article online \\
\hline & $\begin{array}{l}\text { Website: www.gorm.com.tr } \\
\text { e- mail: info@gorm.com.tr }\end{array}$ \\
\hline & DOI:10.21613/GORM.2018.812 \\
\hline
\end{tabular}

How to cite this article: Demirayak G. Guralp O. Yildiz M. Comba C. Mihmanli V. Ozdemir IA. Laparoendoscopic Single-Site Hysterectomy: A Single Surgeon Experience in a Tertiary Hospital. Gynecol Obstet Reprod Med 2019;25(2):96-100

\section{Introduction}

Hysterectomy is one of the most common gynecological operations. Vaginal and laparoscopic approaches are defined as "minimally invasive procedures" since there is no need for wide abdominal incisions. Although the vaginal approach has many advantages, if it is not applicable, laparoscopic surgery should be chosen instead of open surgery (1).

Minimally invasive surgery reduces the duration of hospital stay, lowers postoperative pain scores, and shortens the healing period. In the last ten years, with the improvement in entrance techniques, the need for postoperative analgesia has been reduced and cosmetic results were improved. Laparoendoscopic single-site (LESS) surgery is a new approach in this context, which aims to use the natural embryological orifice: the transumbilical route (2).

Traditionally, three or four-port sites are used in gynecological laparoscopic operations. The main advantage of the LESS surgery is the use of the umbilicus as the port incision. Since the scar is hidden in the umbilicus, these operations are also called scarless operations $(3,4)$. 
The LESS surgery is also performed and scientifically evaluated in appendectomies, cholecystectomies, and various urological procedures (5). The first supracervical hysterectomy through LESS was performed by Pelosi et al. in 1992 (6), and the first total laparoscopic hysterectomy was performed by Lengebrekke et al. in 2008 (7).

The main concept of the LESS surgery is the localization of all the trocars through the same incision (8). For that reason, there are many limitations in the LESS surgery compared to multiport laparoscopy, such as hindrance of free movement of the instruments (crossing/sword-fighting instruments) or angle problems (breakdown of the triangulation) $(3,4)$. Behnia-Willison et al. (9) compared the single- and multi-port laparoscopic approaches and observed that the LESS surgery was associated with better cosmetic results, decreased need for analgesia, and increased patient satisfaction.

In this study, we aimed to evaluate the outcomes of the total hysterectomy cases performed with the LESS surgery.

\section{Material and Method}

A total of 24 women who underwent total hysterectomy by the LESS technique between March 2014 and July 2016 in Okmeydani Research and Training Hospital, Istanbul, Turkey due to benign gynecological disorders were retrospectively evaluated. The study was approved by the Health Sciences University, Okmeydani Education and Research Hospital Ethics Committee (2016 \#409) and was conducted in accordance with the ethical principles described by the Declaration of Helsinki.

Exclusion criteria were conversion to laparoscopy or laparotomy and malign disorders.

Demographic features such as age, body-mass index, parity, previous operations, and indication for hysterectomy were documented. Outcomes such as the duration of the operation (skin incision to skin closure), estimated blood loss, the weight of the uterus, intra- and postoperative complications, pre- and postoperative day 1 hemoglobin and hematocrit levels, postoperative 6- and 24-hour visual analogue scale (VAS) scores, and duration of hospital stay were recorded. The presence of incisional hernia during postoperative follow-up were also registered.

\section{Preoperative Preparation}

Mechanical bowel preparation was not used and a firstgeneration cephalosporin was administered 60 minutes before umbilical incision according to the Enhanced Recovery After Surgery (ERAS) recommendations (10).

\section{Procedure}

All the procedures were performed by a single surgeon (GD). Before the incision, $10 \mathrm{ml}$ of Bupivacaine was injected into the umbilicus. A $2 \mathrm{~cm}$ vertical incision was made in the umbilicus and abdominal cavity was entered. A Octoport single port (DalimSurgNET, Seoul, Korea) was placed (Figure 1). Pneumoperitoneum was achieved. The operation was performed at a $30^{\circ}$ to $45^{\circ}$ Trendelenburg position and a $20^{\circ}$ leftside position. The operator was on the left side of the patient.

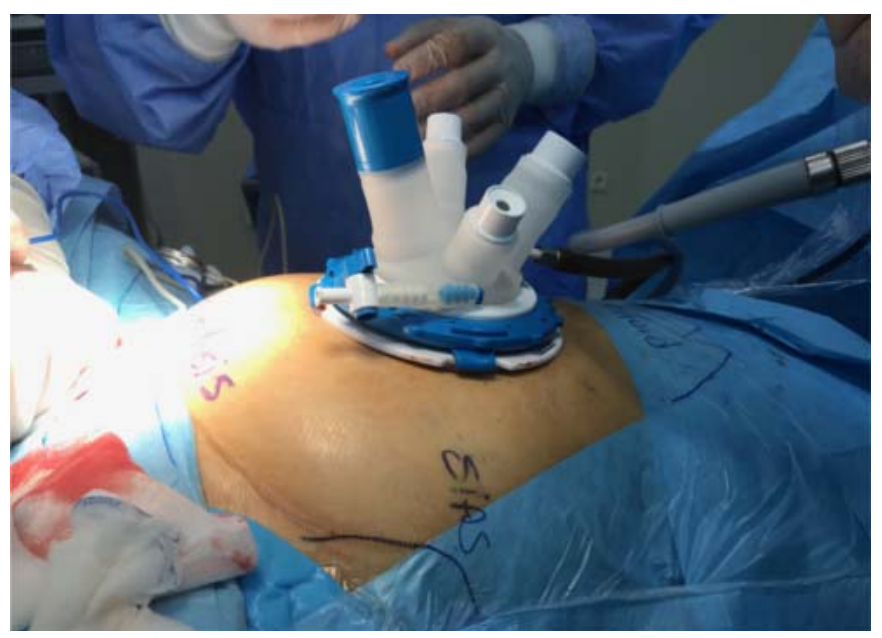

Figure 1: The Octoport (DalimSurgNET, Seoul, Korea) inserted in umbilicus

\section{Hysterectomy Procedure}

A $30^{\circ}, 5 \mathrm{~mm}, 31 \mathrm{~cm}$ long telescope and rigid laparoscopic instruments were used (Figure 2).

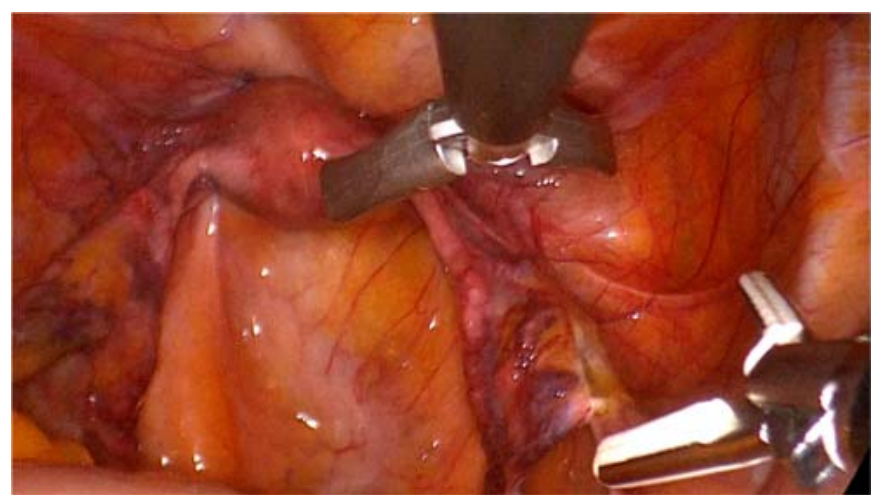

Figure 2: Panaromic imaging of the pelvis and laparoscopic instruments

As an energy source, LigaSure ${ }^{\mathrm{TM}}$ Lap $10 \mathrm{~mm}$ (Valleylab/ Covidien, Boulder, CO, USA) was used. For colpotomy, a monopolar L-hook was used. The Clermont-Ferrand uterine manipulator (Karl Storz, Germany) was used in all cases for uterine manipulating. The round ligaments, ovarian ligaments, and broad ligaments were dissected (Figure 3). The vesicouterine peritoneal fold was opened, and the bladder was mobilized with a monopolar coagulator (Figure 4). The uterine vessels were dissected (Figure 5) with the LigaSure ${ }^{\mathrm{TM}}$ system (Medtronic, Minneapolis, USA), and the vaginal wall was incised circumferentially with a monopolar coagulator (Figure 6). The vaginal cuff closure was performed vaginally in all patients. 


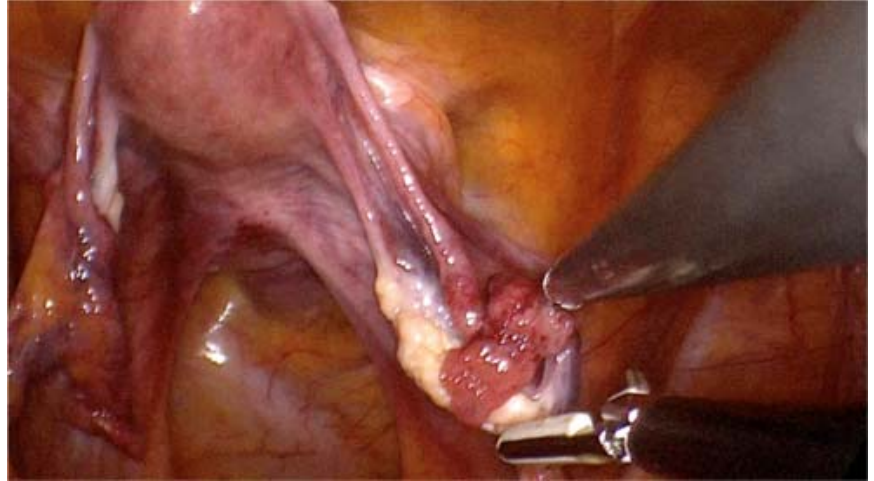

Figure 3: Grasping the infundibulopelvic ligament with the Ligasure (Valleylab/Covidien, Boulder, CO, USA)

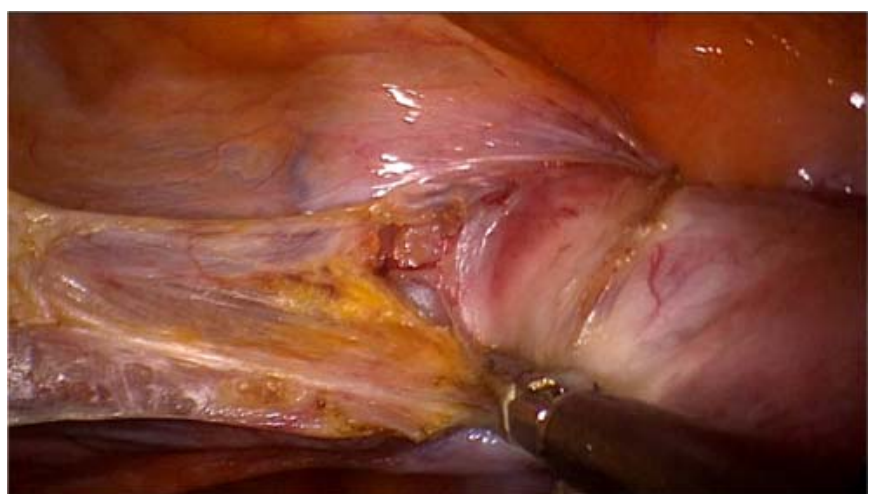

Figure 5: Sealing of the uterine vessels

The VAS scores were evaluated routinely by a gynecology resident.

Homogeneous parametric variables were expressed as mean \pm standard deviation, minimum, and maximum. Nonparametric variables were evaluated with a chi-square test. Statistical analyses were performed using SPSS 22 (Statistical Package for Social Science) for Windows 10.0. A $p<0.05$ value was accepted as significant.

\section{Results}

A total of 141 women underwent total laparoscopic hysterectomy between March 2014 and July 2016 in Health Sciences University, Okmeydani Research and Training Hospital, Istanbul, Turkey. 117 (83\%) women were operated with a conventional multiport laparoscopy; whereas 24 (17\%) women were operated with the LESS technique.

In one patient, LESS was planned; however, due to wide pelvic adhesions, the operation had to be completed with open surgery. This latter case was excluded from the study. Most frequent indications were therapy refractory abnormal uterine bleeding and CIN III lesion by surgical margin. Eight (33\%) of 24 women had a previous surgery. Two women had two ce-

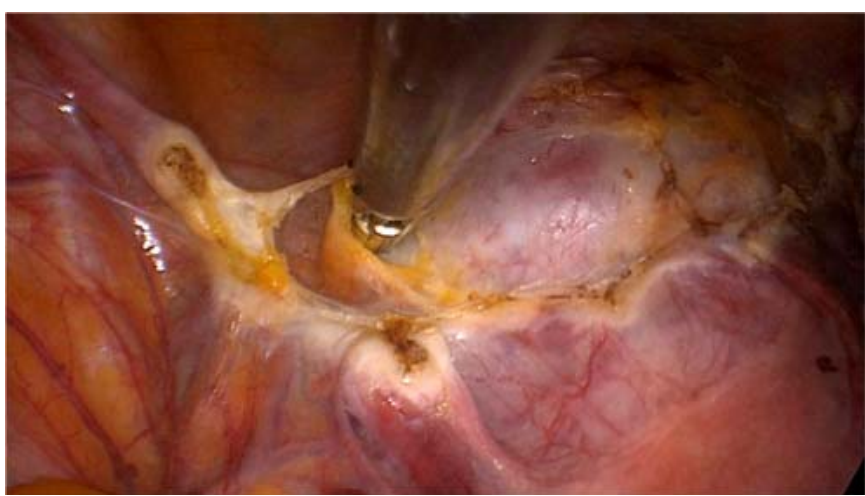

Figure 4: Dissection of the uterovesical fold of the peritoneum and mobilization of the bladder

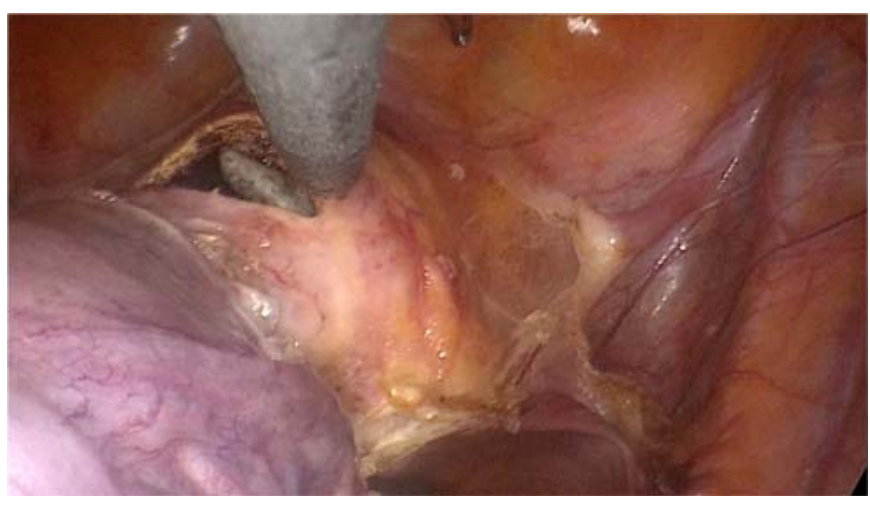

Figure 6: Circumferential colpotomy with the monopolar hook

sarean sections, one woman had one cesarean section, three women had appendectomies, and two women had laparoscopic cholecystectomy in their previous history.

The demographic features of 24 women are shown in table I. The mean age of the patients was $49.3 \pm 6.3$ years. The mean body-mass index was $28.1 \pm 2.9 \mathrm{~kg} / \mathrm{m}^{2}$.

The operative findings of 24 women are shown in table II. The mean total operation time was 112.1 minutes. The average time between the umbilical incision and starting the hysterectomy was $10 \pm 2.1$ minutes.

The mean estimated blood loss was $50 \mathrm{~mL}(5-200 \mathrm{~mL})$. Blood transfusion was not necessary for this series of patients.

The mean uterus weight was $135 \mathrm{~g}$ (80-230 g). The mean difference between the pre- and postoperative hemoglobin values was $1.1 \mathrm{~g} / \mathrm{dL}(0.2-2.1 \mathrm{~g} / \mathrm{dL})$. The mean VAS scores were $4.1(0-7)$ and $1.9(0-4)$ in 6- and 24-hour postoperative periods. None of the women had an intraoperative complication. Thirteen $(54 \%)$ of the 24 women were discharged after 24 hours. One patient had a port site hernia 6 months after the operation and underwent hernia correction in our general surgery department in 12 postoperative months. 
Table I: The demographic features of the patients in the laparoendoscopic single-site group ( $n=24)$

\begin{tabular}{|c|c|c|}
\hline Demographic features & Mean $\pm S D$ & Range \\
\hline Age $(y)$ & $49.3 \pm 6.3$ & $41-65$ \\
\hline Parity & $3.6 \pm 1.4$ & $1-6$ \\
\hline BMI $\left(\mathrm{kg} / \mathrm{m}^{2}\right)$ & $28.1 \pm 2.9$ & $24.5-34.9$ \\
\hline$(n=8.33 .3 \%)$ & $\begin{array}{l}\text { Cesarean section (3) } \\
\text { Appendectomy (3) } \\
\text { Laparoscopic. cholecystectomy (2) }\end{array}$ & $\begin{array}{r}12.5 \% \\
12.5 \% \\
8.3 \%\end{array}$ \\
\hline \multicolumn{3}{|l|}{ Indications for surgery } \\
\hline Abnormal uterine bleeding & 16 & $66.7 \%$ \\
\hline Cervical intraepithelial neoplasia 3 & 5 & $20.8 \%$ \\
\hline Adnexal mass & 2 & $8.3 \%$ \\
\hline Atypical complex hyperplasia & 1 & $4.2 \%$ \\
\hline \multicolumn{3}{|l|}{ Additional surgical procedures } \\
\hline Bilateral salpingo-oophorectomy & 15 & $62.5 \%$ \\
\hline Bilateral salpingectomy & 9 & $27.5 \%$ \\
\hline
\end{tabular}

Table II: Surgical outcomes

\begin{tabular}{lcc}
\hline & Mean \pm SD & Range \\
\hline Estimated blood loss (ml) & $50 \pm 25$ & $5-200$ \\
Duration of operation (min) & $112 \pm 24$ & $65-210$ \\
Duration of hospital stay (day) & $1.5 \pm 0.4$ & $1-2$ \\
Uterine weight (g) & $135 \pm 95$ & $80-230$ \\
\hline
\end{tabular}

SD: Standard deviation, $m L:$ Milliliter, Min: Minute, g: Gram

\section{Discussion}

In accordance with the cosmetic expectations of the patients, the single-port laparoscopic surgery is developing rapidly, with an increasing number of surgeons focusing on this approach (11). In this study, the experience of one surgeon using the LESS technique for a total hysterectomy has been presented.

Single-port laparoscopic hysterectomy is a safe and attainable technique; however, the evidence is not adequate to recommend its widespread use compared with multi-port laparoscopic hysterectomy. Considering the potential benefits such as better cosmetic outcome, single-port laparoscopic hysterectomy may be an alternative technique for the selected patients (12).

In a meta-analysis (13), it has been demonstrated that single-port laparoscopic hysterectomy is generally equivalent to multi-port laparoscopic hysterectomy in terms of intraoperative and postoperative complication rate, postoperative pain, conversion rate, estimated blood loss, and length of hospital stay; on the contrary, single-port laparoscopic hysterectomy requires slightly longer operative time. Comparing the results of the present study with the results of our previous study (14) about conventional multiport total laparoscopic hysterectomy including patients with early stage endometrial cancer, we ob- served that the duration of hysterectomy operation was slightly longer in LESS compared to the conventional multiport technique (112 min vs $104 \mathrm{~min}$ ). Moreover, the complication rates, mean estimated blood loss, and mean duration of hospital stay were comparable.

In the LESS technique, the intracorporeal suturing is more difficult than conventional technique due to the breakdown of the triangulation and crossing/sword-fighting instruments (15).

A recent randomized controlled multicenter study from Italy (16) showed that laparoscopic closure of the vaginal cuff at the end of total laparoscopic hysterectomy was associated with a significant reduction of vaginal dehiscence, any cuff complication, vaginal bleeding, vaginal cuff hematoma, postoperative infection, need for vaginal resuture, and reintervention compared to the transvaginal approach. In our study, the vaginal cuff was sutured by transvaginal method. We did not observe any cuff dehiscence in our case series; however, the number of patients in our study is not enough to draw definitive consequences.

Gumus et al. (17) have shown that in patients who require multiple surgical procedures, including those patients whose diseases extend across multiple disciplines, the necessary procedures can be performed safely and effectively when combined in a single laparoscopic operation. If the other surgeons 
from other disciplines have adequate surgical experience with the LESS surgery, all the procedures may be performed in a single session without any additional incisions.

The port site hernia is probably the main concern after the LESS surgery, and its rate is approximately 5.5\% (18). In accordance with the literature, the port site hernia rate after the LESS surgery was $4.2 \%$ in our study. Nevertheless, in our previous study we did not observe any port site hernia after the conventional multiport surgery (14).

The main weaknesses of our study are its retrospective nature and the low number of patients. Large scaled prospective studies are needed to better evaluate the surgical outcomes and VAS scores.

In conclusion, the total hysterectomy with LESS technique is a reasonable option in selected patients with similar safety and feasibility, especially for women who prefer a single incision in umbilicus. The patient should be informed before the operation about the potential complications such as port-site hernia.

: Acknowledgments: "None"

Funding Statement: "None"

Disclosures: "The authors report no conflicts of interest"

\section{References}

1. Committee Opinion No 701: Choosing the route of hysterectomy for benign disease. Obstet Gynecol. 2017;129 (6):e155-e159.

2. Desai MM, Stein R, Rao P, Canes D, Aron M, Rao PP, et al. Embryonic natural orifice transumbilical endoscopic surgery (E-NOTES) for advanced reconstruction: Initial experience. Urology. 2009;73(1):182-7.

3. Park YS. Current trends of gynecologic surgery in the $21^{\text {st }}$ century: scarless surgery. Korean J Gynecol Endosc Minim Invasive Surg. 2010;22:69-89.

4. Canes D, Desai MM, Aron M, Haber GP, Goel RK, Stein RJ, et al. Transumbilical single-port surgery: evolution and current status. Eur Urol. 2008;54(5):1020-9.

5. Kaouk JH, Haber GP, Goel RK, Desai MM, Aron M, Rackley RR, et al. Single-port laparoscopic surgery in urology: Initial experience. Urology. 2008;71(1):3-6.

6. Pelosi MA, Pelosi MA $3^{\text {rd. Laparoscopic supracervical }}$ hysterectomy using a single-umbilical puncture (mini-laparoscopy). J Reprod Med. 1992;37(9):777-84.
7. Langebrekke A, Qvigstad E. Total laparoscopic hysterectomy with single-port access without vaginal surgery. J Minim Invasive Gynecol. 2009;16(5):609-11.

8. Jung YW, Kim SW, Kim YT. Recent advances of robotic surgery and single port laparoscopy in gynecologic oncology. J Gynecol Oncol. 2009;20(3):137-44.

9. Behnia-Willison F. Foroughinia L. Sina M. Mc-Chesney P. Single incision laparoscopic surgery (SILS) in gynaecology: feasibility and operative outcomes. Aust N Z J Obstet Gynaecol. 2012;52(4):366-70.

10. Nelson G, Altman AD, Nick A, Meyer LA, Ramirez PT, Achtari C. et al. Guidelines for pre- and intra-operative care in gynecologic/oncology surgery: Enhanced Recovery After Surgery (ERAS ${ }^{\circledR}$ ) Society recommendations - Part I. Gynecol Oncol. 2016;140:313-22

11. Fancellu A, Rosman AS, Sanna V, Nigri GR, Zorcolo L, Pisano M, et al. Meta-analysis of trials comparing minimally-invasive and open liver resections for hepatocellular carcinoma. J Surg Res. 2011;171(1):e33-45.

12. Xie W, Cao D, Yang J, Yu M, Shen K, Zhao L. Single-port versus multi-port laparoscopic hysterectomy: A metaanalysis of randomized controlled trials. J Minim Invasive Gynecol. 2016;23(7):1049-56.

13. Sandberg EM, Chapelle CF, van den Tweel MM, Schoones JW, Jansen FW. Laparoendoscopic single-site surgery versus conventional laparoscopy for hysterectomy: a systematic review and meta-analysis. Arch Gynecol Obstet. 2017;295(5):1089-103.

14. Demirayak G, Kılık T, Cetinkaya FN, Bulut B, Akbas M, Kilınc A, et al. Laparoskopik histerektomi deneyimlerimiz. Okmeydanı T1p Derg. 2016;32(4):198-203.

15. Fader AN, Escobar PF. Laparoendoscopic single-site surgery (LESS) in gynecologic oncology: technique and initial report. Gynecol Oncol. 2009;114(2):157-61.

16. Uccella S, Malzoni M, Cromi A, Seracchioli R, Ciravolo G, Fanfani F, et al. Laparoscopic vs transvaginal cuff closure after total laparoscopic hysterectomy: a randomized trial by the Italian Society of Gynecologic Endoscopy. Am J Obstet Gynecol. 2018;218(5):500.e1-500.e13.

17. Gumus II, Surgit O, Uysal A, Simavlı S, Eser A, Kaygusuz I. Minimally invasive approaches for combined gynecologic surgeries: Our three years clinical experiences. Gynecol Obstet Reprod Med. 2015;21:97-101.

18. Moulton L, Jernigan AM, Carr C, Freeman L, Escobar PF, Michener CM. Single-port laparoscopy in gynecologic oncology:seven years of experienceat a single institution. Am J Obstet Gynecol. 2017;217(5):610.e1-610.e8. 